\title{
NAS BRECHAS DO PODER: FRAGMENTOS DO TRABALHO DO PSICÓLOGO NAS VARAS DE INFÂNCIA E JUVENTUDE
}

\author{
Siglia Cruz de Sá Leão \\ Jessica Mara Oishi
}
O homem sem qualidades é aquele cujo destino é o de não ter nenhuma outra qualidade senão a de ser marcado pelo 1 e, deste modo, poder entrar na quantidade.
[... o o homem sem qualidades é o homem quantitativo.

Jacque-Alain Miller, em A era do homem sem qualidades

O trabalho do psicólogo na instituição judiciária é o pano de fundo para este capítulo que visa propor reflexões sobre o cuidado e a proteção da infância e da juventude, bem como expor dilemas que compõe nosso cotidiano e prática profissional na lide com crianças e adolescentes, sujeitos de Direito.

Ainda que a concepção da criança e do adolescente como sujeitos de direitos seja reconhecida a partir da Constituição de 1988, somente com a promulgação do Estatuto da Criança e do Adolescente (ECA), em 1990, um novo paradigma se confirma, historicamente construído ao longo do processo de produção e proteção da infância. Outras disciplinas e especialidades também passaram a ser chamadas, no território jurídico, a se ocupar da infância, sendo este o contexto de inserção da Psicologia como partícipe da equipe multidisciplinar que assessora o magistrado.

Como psicólogas que trabalham na Vara da Infância e Juventude, somos convocadas, pelo juiz, a realizar avaliações, propor intervenções e oferecer esclarecimentos, por meio de relatórios técnicos ou laudos, recebidos por este como provas processuais e subsidiárias de decisões.

Usualmente, os casos que se encontram na Vara da Infância e Juventude referem-se a crianças e/ou adolescentes considerados em situação de risco e/ou vulnerabilidade, em razão da violação de direitos por parte dos pais, da família ou da sociedade. A finalidade da intervenção judiciária é garantir que esses direitos sejam restabelecidos e assegurados.

Nesse cenário, a criança e o adolescente figuram no elenco como atores principais. No palco cotidiano, porém, nem sempre protagonizam a cena, "roubada" pelos discursos das diversas disciplinas que constituem o processo e configuram saberes sobre a criança e o adolescente, definindo poderes de fala e autoridade que afetam aqueles sujeitos. 
Apresentaremos dois recortes de casos acompanhados por nós, ao longo deste período de trabalho no Judiciário, com a intenção de ilustrar questões que perpassam nossa prática e provocar e aprofundar reflexões.

\section{ADOLESCÊNCIA: CUIDAR DE SI — FALAR DE SI}

"Após o desaparecimento dos genitores, um grupo de I I irmãos passa a ser acompanhado pelos serviços de proteção e assistência da comunidade. Enquanto os adolescentes são incentivados a adquirir autonomia, conseguir meios de subsistência e gestão da própria vida, as quatro crianças do grupo são encaminhadas a um serviço de acolhimento institucional (SAICA).

A passagem da infância a adolescência, para estes irmãos, é vivida dentro de uma instituição, onde permaneceram por oito anos. Ainda que tenham recebido visita do grupo fraternal, ao longo desse período, a construção da história de vida de cada um, a compreensão dos sentimentos, do desamparo, das fragilidades, é concretizada com apoio dos técnicos da instituição, bem como por meio de um projeto promovido por uma ONG. Convidados a relatar suas histórias para composição de um livro, os quatro adolescentes prontamente aceitam. Em razão da condição de tutelados pelo Estado, havia necessidade de solicitar autorização do juiz para tornar as histórias públicas por meio de um livro.

A equipe do serviço de acolhimento é convocada a se manifestar sobre o pedido, bem como a equipe técnica do judiciário (psicóloga e assistente social). Em todas as manifestações, há a defesa da importância do resgate da história de vida dos adolescentes e registro destas informações, sendo um desejo de cada um dos irmãos revelar suas conquistas ao longo da vida, explicitar o orgulho que sentiam de terem conseguido superar as adversidades e apresentar os planos de futuro para quando atingissem a maioridade civil.

○ juiz indefere o pedido, justificando que a história de desamparo pessoal/familiar e de um longo período de acolhimento institucional não é uma história de sucesso, sendo importante, em nome de uma proteção aos adolescentes, resguardá-los de possíveis situações vexatórias, o que implicaria em não veicular tais histórias, ou veiculá-las de maneira anônima, como, por fim, foi feito".

Gostaríamos de destacar, no relato apresentado, a justificativa evocada por esse magistrado de insucesso, ou seu equivalente o fracasso, que marca as histórias dos adolescentes. Identifica-se a justaposição de duas afirmativas que permitem entrever a preocupação de êxito institucional na realização de uma determinada tarefa (acolhimento institucional $X$ colocação em família) e a valoração da experiência de vida daqueles sujeitos.

A qualificação de fracasso associa-se ao ato final ou o resultado alcançado ao longo do tempo de acompanhamento do processo judicial, nesse caso a continuidade da experiência de acolhimento institucional dos adolescentes pelo período de oito anos. De acordo com as legislações atuais, a medida de acolhimento institucional deveria ser provisória, espaço de trânsito entre convivências familiares. Um dos direitos fundamentais de crianças e adolescentes é a inserção e permanência no meio familiar, que, muitas vezes, configura-se como um ideal e uma exigência, sendo a ausência deste lugar-família associada ao não desenvolvimento pleno e à existência de riscos aos sujeitos. A unidade família constituiu-se como um valor universal e um lócus, por excelência, em que a criança/adolescente deveria permanecer. 
A família contemporânea, que se desenha a partir das estratégias médico-higiênicas, estrutura-se na concepção da maternidade como natural e ligada à criação e educação dos filhos, no processo de valorização da infância e reorganização do ambiente doméstico, alçando os filhos à posição de prioridade, assim como na ênfase e construção do afeto e da afetividade como pontos centrais das relações familiares. Paulatinamente, constitui-se uma normatividade familiar: a criança passa a definir a família e este núcleo assim fundamentado torna-se o passaporte que garante o pertencimento desta a uma norma e ideal'.

A impossibilidade de inclusão do grupo de irmãos em um ambiente familiar e a permanência destes em uma instituição configuram o olhar e o entendimento do caso como fracasso, impedindo que o vínculo estabelecido entre eles desenhe o lugar-família e situando-os à margem da normatividade. $\bigcirc$ termo utilizado, neste contexto, qualifica o processo institucional como um todo que não alcançou seu devido objetivo de colocação dos adolescentes em família (biológica ou substituta). De que fracasso estamos falando? Distanciados do olhar singularizado lançado àqueles sujeitos concretos, a marca recai no impedimento à garantia de um direito-dever de convivência familiar, eixo fundamental do trabalho da Vara da Infância e Juventude e seus atores institucionais.

Atentos às narrativas de vida daqueles adolescentes, notamos que há relatos de dificuldades, mas também de superações. As histórias não eram construídas exclusivamente por felicidades ou prazeres, mas continham toda gama de sentimentos e movimentos vitais, incluindo dor e sofrimento. Este é o segundo enunciado que se veicula: a representação do fracasso como qualificador dessas experiências de vida, a circunscrição e delimitação da violência, miséria, desamparo e tristeza como indicativos de fracasso, em oposição aos indicativos de sucesso, felicidade e bem-viver.

A felicidade é decantada em mensagens publicitárias, pesquisas acadêmicas e projetos políticos, como "o alfa e o ômega da existência" - a mola propulsora de todas as ações humanas, a obrigação e o direito primordial de cada um de nós. (Freire Filho, 20 l0, p.13)

Desde a Revolução Francesa a felicidade deixou de ser uma moral individual para converter-se em aspiração social e um fator de política (Brodsky, 2009). A combinação entre utopia social e projeto político, de governo, estava delineada. Apoiada em Lacan, a autora faz uma reflexão sobre a apologia da felicidade, apontando para "as grandes utopias, que planejaram um paraíso para todos na Terra, como um achatamento, mais ou menos metafórico [...] do singular no universal" (p.13). Essa busca da felicidade de todos - de que "não poderia haver a satisfação de ninguém fora da satisfação de todos" - recai em paradoxos: a apologia da felicidade e a crueldade (Lacan apud Brodsky, 2009, p. 13).

A felicidade deixa de figurar como um direito, uma possibilidade de satisfação de um, para tornar-se um dever de todos. Bruckner (2000) delineia esse processo de deslocamento do movimento de busca da felicidade e evitação do desprazer e da dor, inerente

I Há muitos autores que discutem essa questão, como Costa (1999), Ayres (2009) e Badinter (1985). 
ao humano e ao vivente, que, na sociedade contemporânea, constituiu-se no imperativo de felicidade, intolerância ao sofrimento - e, mesmo, utopia higienista.

$\bigcirc$ mundo atual nos conduz a uma constante busca por narrativas bem-sucedidas, experiências de vitórias e enunciados de felicidade, enquanto as vivências de dor e sofrimento, frustrações e fracassos geralmente são empurradas ao esquecimento, à negação, à silenciosa conformidade, aos eficientes medicamentos, desqualificadas como constitutivos da subjetividade e da identidade dos indivíduos. As estratégias de medicalização da vida e patologização da tristeza, centradas, prioritariamente, no anestesiar de dores e reposicionamento da alegria e felicidade ao centro das emoções do sujeito, guardam consonância com a lógica econômica e as demandas do mercado. Vulnerabilidade, desamparo, sofrimento assinalam o "mal-viver", uma vida menos valiosa e produtiva.

As vivências de sofrimento desses quatro adolescentes, índice de fracasso pessoal, precisam ser, segundo a ordem, enclausuradas e limitadas, temporal e espacialmente, aos perímetros da esfera privada. $\bigcirc$ sofrimento não encontra seu espaço de manifestação. Os adolescentes, impedidos de nomearem suas próprias histórias, ficam reduzidos ao anonimato, processo que se opera de invisibilização da vida.

Em nome de uma suposta proteção, o que se erradica não é, nesse caso, a possível violência advinda de uma vexatória exposição, mas a subjetividade. A violência, ao contrário, a vemos produzida no seio da instituição que deveria combatê-la, marcada esta pelo avanço do discurso cientificista, a serviço do mercado e do consumo, que anunciam a garantia de felicidade para todos.

\section{AUTÔNOMO, AUTÔMATO, AUTISTA...?}

"A Vara da Infância e Juventude recebe a informação do acolhimento institucional de uma criança de I I anos, com a afirmação de que era autista, porém sem exames comprobatórios do diagnóstico. Com a mãe falecida e tendo o pai desaparecido por uso de drogas, o acolhimento foi justificado tendo em vista que a única referência familiar - uma tia -, ao ser procurada pelo Conselho Tutelar, teria revelado sua impossibilidade de cuidar da criança por imaginar o trabalho que teria que dispensar a ela, dado o suposto diagnóstico.

Ao conhecer a criança, os profissionais do Serviço de Acolhimento revelam outra impressão, considerando-a amorosa e tranquila. Observam, ainda, que ela parecia tentar se comunicar e se relacionar, apesar do mutismo apresentado. O diagnóstico parecia-Ihes questionável, porém, assim que foi ratificado pelo psiquiatra da rede de saúde que atendia as crianças da instituição, transformou-se em passaporte para a solicitação de transferência do menino para um local apropriado, especializado em crianças autistas, onde ele pudesse ficar internado, frequentar escola especial ou uma instituição em que aprendesse algo de trabalho e treino de técnicas.

A partir daí, o juiz determina que a equipe técnica da Vara da Infância e Juventude (psicóloga e assistente social) entreviste a criança e colha eventual informação de atendimento da mesma no hospital psiquiátrico infantil da cidade, por ser autista sem familiar conhecido e com vistas à autonomia. O relatório apresentado pelas profissionais do juízo aponta, para além da informação solicitada, a posição da criança perante o mundo, suas particularidades e necessidades, escutadas no encontro que tiveram. A criança, ao seu modo, parecia ter descoberto um bom lugar de circulação no serviço 
de acolhimento e aparentava ter ali a segurança necessária para o seu desenvolvimento. Ainda, extraiu-se que precisava de tratamento para que pudesse endereçar suas questões, sofrimentos, sintomas, bem como ampliar suas possibilidades de estabelecimento de laço social. Para tanto, foi sugerida sua inserção no equipamento de saúde especifico da região e também o retorno à escola.

A insatisfação do magistrado com a resposta apresentada por sua equipe interdisciplinar foi notória, gerando nova determinação: a de que a criança fosse levada para o hospital psiquiátrico, que era quem deveria fazer a avaliação e correto encaminhamento do caso, reiterando, com vistas à autonomia".

A partir do extrato acima, interessa-nos iluminar os princípios sobre os quais se apoia o discurso veiculado por esse juiz, em nome dos direitos das crianças e adolescentes. Evidenciase que seu interesse não era saber da criança ou o saber da criança, mas da avaliação médica especializada, do diagnóstico cientificamente comprovável e o prognóstico. Sob a face do pragmatismo e objetividade, cuidado e proteção da criança, o que se revela é a exigência de uma resposta verdadeira e de uma saída eficiente para a situação. A solicitação de categorias, classificações, mensurações e previsões traz subjacente o princípio da utilidade. Vemos emergir um discurso que se autoriza da eficácia da ciência - de suas prescrições, pesquisas e evidências supostamente incontestáveis - produzindo de fato a segregação da diferença.

Tarrab (20II) afirma que "para a sociedade da eficiência, o sintoma e a angústia são intoleráveis". Intolerável para o juiz abrir uma brecha e fazer passar o saber de uma criança com um possível "distúrbio do espectro autista". O que se impunha como necessário era saber o quanto antes do distúrbio e sua solução, e não da criança e suas questões: o saber da Medicina chamado a dar suporte ao saber do Direito.

Travestida da intenção de busca do bom e libertador ato terapêutico e educativo - a autonomia, repetidas vezes referida - o que se desnuda é o afã tecnocrático da determinação judicial em questão. Haveria uma técnica capaz de ajustar a criança ao bom trato social, permitindo-Ihe uma saída da instituição acolhedora sobre a qual o poder judiciário era o responsável? Seria o menino capaz de gerir sua própria vida ou quanto tempo seria necessário para que se tornasse capaz? Teria a criança condições de ser treinada a fazer algo útil e socialmente adaptado? Seria possível adequá-la para um retorno à convivência familiar por meio de sua família extensa ou substituta (ainda que nesse caso a dificuldade fosse maior)?

Essas perguntas não formuladas, subjacentes à explicitada questão quanto ao eficaz tratamento à medida de autonomia, tangenciam outras como a da medida legal mais eficiente ${ }^{2}$, os rumos do investimento do Estado, o índice de produtividade do magistrado, calculado, entre outros, por meio dos números de desacolhimento institucional.

Essa criança era forte candidata a ser mais uma a engrossar o caldeirão do fracasso dos "sem-familia" e com longa história institucional. No caso dela e dos quatro adolescentes citados, ficava difícil cumprir a meta colocada na Lei n 12.010/09, de dois anos de acolhimento

2 A diferença entre os critérios de eficácia e eficiência são assinalados por Barton (2007), que aponta ser a eficiência um critério de administração, podendo ser quantificável; já a eficácia, só aplicável ao exercício de uma prática, não se presta a quantificações, só pode ser demonstrada no caso a caso. A confusão desses critérios, a imiscuição da eficiência na eficácia se faz mister na era de uma política de resultados rentáveis. 
institucional. O tempo balizador se torna escravizador, medida de êxito institucional, ressoando "a voz terrível do supereu contemporâneo, encarnado nos ideais profiláticos e higienistas que hoje em dia monopolizam o interesse social" (Barton, 2007, p. I27).

A família é o melhor lugar em que a criança pode encontrar, nos diversos saberes, boas e legítimas justificativas. A questão é quando ela se torna ideal a ser cumprido, meta a ser perseguida, transformando-se em número almejado, instrumento de controle. A lista de crianças que retornaram ou não à convivência familiar é preciosidade no Juízo da Infância.

\section{CONSIDERAÇÕES FINAIS}

Cientes das especificidades e particularidades de cada caso, parece-nos que os dois relatos apresentados conversam em seus fracassos, mutismos, na ausência familiar, com suas consequências jurídicas, bem como na violência institucional reproduzida.

Ambas explicitam a lógica que assola o momento atual. Não poucas vezes, quer seja no âmbito jurídico, da saúde ou da educação, crianças e adolescentes ficam apagados pela dimensão do acontecido. Genericamente identificados apenas por rótulos, diagnósticos, vivem sob efeito de violências mais silenciosas, produzidas pelas medidas de proteção ou ainda por saberes especializados que fazem deles (crianças e jovens), a "vítima totalmente designada do saber", como aponta J-A. Miller (2012, p.6). O saber disciplinar comprimindo o saber autêntico de cada um, de cada criança sobre o que lhe é próprio.

Essa lógica está intimamente relacionada à política das avaliações, que visa ao controle, à previsibilidade do sujeito, tomado em sua condição de objeto a ser programado, medido, calculado, inclusive nos riscos possíveis. No afã da proteção, da "Ciência Protetiva", do Direito preservado, o modelo atual de gestão social se explicita por meio de mecanismos de controle que apontam para a homogeneização e a normatização.

Adverte-nos J-A. Miller (2005):

somos todos quantificáveis e quantificados. Isto pode não nos agradar, porém, o modo atual, o modo contemporâneo de gestão da sociedade passa pela quantificação, fazendo mesmo com que ela reine de maneira exclusiva, já que o discurso universal não tem mais outras qualidades, outras identificações a nos propor que se sobreponham ao I da fila, o I que nos torna contáveis e comparáveis [...] $\bigcirc$ significante-mestre como unidade contável é $[. .$.$] o mais$ elaborado pois é justamente limpo de qualquer significação. Ele conduz ao que é, aparentemente, uma necessidade das sociedades contemporâneas: o estabelecimento de listas. (p.3)

Eis o regime das cifras invadindo os saberes. Nessa lógica, cada criança, ao entrar no campo jurídico para ser protegida, ganha um número, uma etiqueta e a pertinência a uma lista: acolhida, adotável, não adotável, desacolhida etc. A tendência é a homogeneização dos sujeitos e suas histórias, subsumidos a categorias. $\bigcirc$ incremento ou diminuição do 
número de crianças sob certa etiqueta é vigiado pelo grande olho estatal preocupado com a manutenção da norma, os rumos do investimento a ser feito. $\bigcirc$ magistrado, nesse enredo, muitas vezes pressionado pela medida estatística que o posiciona em outra listagem, a de produtividade, sucumbe à avaliação baseada nas evidências e, como mestre cego, faz-se visível agente da letra fria da lei, que "duplica a mão invisível do mercado"3 (Laurent apud Barton, 2007, p. I28).

Não apenas ele, cada ator no cenário jurídico sofre do empuxo de se transformar em expoente reprodutor das políticas de controle social dos corpos infantis, em ilustre protetor da norma em detrimento do sujeito de direito em questão - a criança e o adolescente.

Nessa engrenagem, estão os diversos profissionais do campo da justiça, saúde e educação enredados na "grande aliança entre administração pública, ciência e mercado, que selou-se através da gestão biopolítica das populações" (Barros-Brisset, 20।2, p.5).

Nesse contexto, não é pouco comum encontrar profissionais:

embaraçados, inibidos e silenciados pelo furor institucional a exigir o cumprimento cego de procedimentos visando contabilizar resultados consonantes com o projeto de gestão. Protocolos determinam como as intervenções das equipes devem acontecer, engessando a prática através do molde 'como o mestre mandar'. O saber fazer de cada um é apagado pelo dever fazer protocolar (Barros-Brisset, 2012, p.6-7).

Nesse movimento, apagam-se os traços singulares, a criatividade dos sujeitos (profissionais e crianças), dissolvidos na amplitude das técnicas aplicadas e determinações cumpridas. Será possível resistir a essa lógica, recusar esse lugar? Embrenhadas dentro da instituição jurídica, supomos que sim, desde que não recuemos à batalha diária na tentativa de escapar das burocracias, localizando as construções e cristalizações institucionais e nossas possibilidades neste campo. Escapemos das armadilhas cotidianas a obnubilar o olhar e a nos ensurdecer às falas das crianças e adolescentes que por ali transitam, exercendo uma escuta orientada para a singularidade e a subjetividade.

Aceitemos o desafio de fazer uso de nossas armas, oferecidas pelas disciplinas críticas e pela psicanálise, e enfrentemos esses fenômenos característicos de nossa época, favorecendo uma práxis que possibilite a emergência de um novo saber, que não o das categorias, e brechas, por onde escoe o desejo não anônimo de cada criança e de cada profissional.

Desde que possamos recusar a ilusão e a exigência de uma verdade única e atentar para os regimes de produção de verdade no campo jurídico, indissociáveis dos mecanismos de poder e de sujeição.

3 Laurent, E. (1994). Estado, sociedad, psicoanálisis. Uno por Uno 40, 34-35. 


\section{REFERÊNCIAS BIBLIOGRÁFICAS}

Ayres, L. S. M. (2009). Adoção: de menor a criança, de criança a filho. Curitiba: Juruá.

Badinter, E. (1985). Um amor conquistado: o mito do amor materno. Rio de Janeiro: Nova Fronteira.

Barros-Brisset, F. O. (20।2). Furando etiquetas - O traço da política do CIEN. Cien-digital, 12, 05-07. Recuperado de http://minascomlacan.com.br/wp-content/uploads/20 15/02/ CIEN-Digital-12-.pdf

Barton, P. T. (2007). Estatísticas. Opção Lacaniana, 50, (edição especial), 126- 129.

Brasil. (1988). Presidência da república. Casa Civil. Subchefia para Assuntos Jurídicos. Constituição da República Federativa do Brasil de 1988. Recuperado de http://www.planalto. gov.br/ccivil_03/constituicao/constituicao.htm.

- (1990). Presidência da República. Casa Civil. Subchefia para Assuntos Jurídicos. Lei no 8.069, de 13 de julho de 1990. Dispõe sobre o Estatuto da Criança e do Adolescente e dá outras providências. Recuperado de http://www.planalto.gov.br/ccivil_03/leis/L8069.htm.

. (2009). Presidência da República. Casa Civil. Subchefia para Assuntos Jurídicos. Lei n $n^{\circ}$ 2.010, de 3 de agosto de 2009. Dispõe sobre adoção: altera as Leis no 8.069/1990 e 8.560/1 992; revoga dispositivos da Lei no $10.046 / 2002$ e da Consolidação das Leis do Trabalho - CLT. Brasilia, DF: Presidência da República, Casa Civil. Recuperado de http://www.planalto. gov.br/ccivil_03/_ato2007-20 I 0/2009/lei//I 20 I 0.htm.

Brodsky, G. (2009). Conferências: as utopias contemporâneas. Carta de São Paulo - Boletim da Escola Brasileira de Psicanálise. (Edição especial) |6, 7-31.

Bruckner, P. (2002). A euforia perpétua: ensaio sobre o dever da felicidade. Rio de Janeiro: Difel.

Costa, J. F. (1999). Ordem médica e norma familiar. Rio de Janeiro: Edições Graal.

Freire-Filho, J (Org.). (20 I0). Ser feliz hoje: reflexões sobre o imperativo da felicidade. Rio de Janeiro: FGV.

Miller, J-A. (2005). A era do homem sem qualidades. Opção Lacaniana Online, I. Recuperado de http://www.opcaolacaniana.com.br/antigos/nl/pdf/artigos/jamera.pdf.

. (20 12). A criança e o saber. Cien-digital, I I, 5-9. Recuperado de http://minascomlacan.com.br/wp-content/uploads/2015/02/CIEN-Digital- I I.pdf.

Tarrab, M. (20 I I). Niños en el mundo del control. Pagina I 2/Rosario 12. Recuperado de https:/www.pagina I 2.com.ar/diario/suplementos/rosario/2 I-30 I36-20 I I-08-25.html. 